\title{
IMPACT OF SINGLE AND TWO-PHASE DISSOLVED OXYGEN TENSION CONTROL ON Bacillus thuringiensis CULTIVATION AND $\delta$-ENDOTOXIN PRODUCTION
}

\author{
MOHAMED MAZMIRA MOHD MASRI ${ }^{1 *}$, MOHD SHAWAL THAKIB MAIDIN ${ }^{1}$ and \\ ARBAKARIYA BIN ARIFF ${ }^{2}$ \\ ${ }^{1}$ Entomology and Integrated Pest Management Unit, Biology and Sustainability Research Division, \\ Malaysian Palm Oil Board, 43000 Kajang, Selangor, Malaysia \\ ${ }^{2}$ Department of Bioprocess Technology, Faculty of Biotechnology and Biomolecular Sciences, \\ Universiti Putra Malaysia, 43400 UPM Serdang, Selangor, Malaysia \\ EE-mail:mazmira@mpob.gov.my
}

Accepted 18 February 2021, Published online 30 March 2021

\begin{abstract}
Constant $\delta$-endotoxin production is crucial in Bacillus thuringiensis cultivation with aeration strategy playing a significant role in the process. In this study, the impact of DOT control strategies on the cultivation performance of B. thuringiensis was investigated using a 5-L stirred tank bioreactor. Single-phase DOT control recorded low spore count $\left(<5.0 \times 10^{11}\right.$ spore $/ \mathrm{mL}$ ) and low percentage of sporulation $(<45 \%)$. Two-stage DOT control cultivation with DOT at $80 \%$ during the active growth phase, followed by a switch to $60 \%$ or $40 \%$ at mid-exponential growth phase contributed to enhanced sporulation $(>60 \%)$, high maximum cell count $(1.5 \mathrm{cfu} / \mathrm{mL})$ with $\delta$-endotoxin formed as early as $8 \mathrm{hr}$ of cultivation. A high maximum specific growth rate, $\mu_{\max }\left(>0.1 \mathrm{~h}^{-1}\right)$ was also essential in ensuring $\delta$-endotoxin production. High cell count obtained in cultivation with DOT level of $80 \%$ saturation during active growth was concurrent with high cell count, high $\mu_{\max }$, fast generation time, high OUR, high CER value, and high respiratory quotient (RQ) value. During the two-phase DOT control cultivation, low RQ values were reported. The result showed that the exhaust gas data could be used to monitor $B$. thuringiensis cultivation performance.
\end{abstract}

Key words: Aeration strategy, dissolve oxygen tension, Bacillus thuringiensis, $\delta$-endotoxin, high sporulation

\section{INTRODUCTION}

Bacillus thuringiensis is a Gram-positive bacterium with the ability to produce spore, parasporal crystal protein (ICPs), and $\delta$-endotoxin. The toxin can be used to combat some agricultural pests and vectors of diseases (Bravo et al., 2011). Almost $90 \%$ of the microbial biopesticide products in the market are dominated by one entomopathogenic bacterium, which is B. thuringiensis (Kumar \& Singh, 2015). Submerged culture is widely used for the industrial production of endotoxin-spore suspension of $B$. thuringiensis. A suitable aeration strategy during the cultivation of $B$. thuringiensis is required to enhance $\delta$-endotoxin formation during sporulation (Sarrafzadeh et al., 2005). The importance of dissolved oxygen tension in the culture during $B$. thuringiensis cultivation has also been pointed out

\footnotetext{
* To whom correspondence should be addressed.
}

by several researchers (Rowe et al., 2003; Maldonado-Blanco et al., 2003; Sarrafzadeh \& Navarro, 2006; Bravo et al., 2015).

A better understanding of the factors that affect oxygen transfer in aerobic cultivation is required to improve the production of the target products. Data on the respiration of microorganisms can be generated using non-proliferating suspensions and low viability suspensions in manometric apparatus. The use of the Warburg apparatus to analyze bacterial respiration has been reported (Stanbury et al., 2003; Lalke-Porczyk \& Donderski, 2001). Another technique to measure gaseous exchange in microbial cultivation is by using a continuous-flow recording respirometer, which is a dissolved oxygen probe that senses the oxygen demand of the culture by constant-current electrolysis of water and is measured by recording the operating time of the power supply (Vanrolleghem, 2001; Kim et al., 2008; Zhang \& Hughes, 2004). Several other techniques 
such as selective absorption of the component gases or gas chromatography (Cheung et al., 2009; Hildebrand, 2010) and continuous recording of pressure changes using manometers or pneumatic transducers (Kuphaldt, 2008) have also been used to measure gaseous exchange during the cultivation.

The effect of dissolved oxygen in the culture on the sporulation rate of $B$. thuringiensis and the synthesis of $\delta$-endotoxin is not well understood and documented. B. thuringiensis is an aerobic bacterium, and it is practical to contemplate the level of dissolved oxygen present in the bioreactor as the main factor in the production of bioinsecticides (Amicarelli et al., 2010). It was reported that the most toxic product of $B$. thuringiensis subsp. israelensis was obtained in cultivation at high aeration rates (Maldonado-Blanco et al., 2003). High dissolved oxygen tension (DOT) of up to $100 \%$ saturation was required during the cultivation to increase the toxic activity of $B$. thuringiensis (Boniolo et al., 2012). Growth of $B$. thuringiensis subsp. H14 was enhanced in well-aerated culture, but the synthesis of $\delta$ endotoxin was significantly repressed (Zuoari et al., 2002). It was also reported that in batch fermentation of $B$. thuringiensis israelensis, there was a marked increase in biomass production with the simultaneous increase of the larvicidal compound (Gopinathan et al., 2016). Significant effect of oxygen supply was reported not only on $B$. thuringiensis, but also on other Bacillus strains such as Bacillus subtilis (Ha et al., 2018). Appropriate control of DOT during the cultivation of $B$. thuringiensis has been reported as one of the crucial factors for the enhancement of $\delta$ endotoxin synthesis (Avignone-Rossa et al., 1992; Aronson, 2002; Bravo et al., 2011).

The objective of this study is to investigate the impact of a single-phase and a two-phase DOT control on $B$. thuringiensis cultivation and $\delta$-endotoxin production in a stirred tank bioreactor cultivation. The results obtained can be applied to up-scale $B$. thuringiensis fermentation with high sporulation and constant $\delta$-endotoxin production.

\section{MATERIALS AND METHODS}

\section{Microorganism}

Bacillus thuringiensis MPK13 was obtained from the culture collection at Entomology and Integrated Pest Management Unit, Malaysian Palm Oil Board (MPOB) Headquarters, Malaysia. This bacterium was locally isolated from soil in the oil palm plantation and was cultivated three times from the dead lepidopteran larvae. This bacterium was isolated from the gut of the dead larvae of bagworm, Metisa plana through several isolation steps. The isolated bacterium was then grown on nutrient agar and stored at $4^{\circ} \mathrm{C}$ as a stock culture (Mazmira et al., 2013).

\section{Cultivation media}

The $B$. thuringiensis strains were cultivated in liquid media at the optimal conditions for $\delta$-endotoxin production. The medium consisted of $(\mathrm{g} / \mathrm{L})$ : $\left(\mathrm{NH}_{4}\right)_{2} \mathrm{SO}_{4}, 2.0: \mathrm{K}_{2} \mathrm{HPO}_{4} \cdot 3 \mathrm{H}_{2} \mathrm{O}, 0.5: \mathrm{MgSO}_{4} .7 \mathrm{H}_{2} \mathrm{O}, 0.2$ : $\mathrm{MnSO}_{4} \cdot 4 \mathrm{H}_{2} \mathrm{O}, 0.05 ; \mathrm{CaCl}_{2} .2 \mathrm{H}_{2} \mathrm{O}, 0.08$; and yeast extract, 2.0 was used as the basal medium (Jaquet et al., 1987; Içgen et al., 2002). Glucose at a concentration of $8 \mathrm{~g} / \mathrm{L}$ was used as the main carbon source (Mazmira et al., 2013). The medium was sterilized at $110^{\circ} \mathrm{C}, 15 \mathrm{~min}$ at $15 \mathrm{psi}$. The initial $\mathrm{pH}$ of the medium was adjusted in the region of $6.5-7.0$ using $1 \mathrm{M} \mathrm{HCl}$.

\section{Cultivation using 5-L stirred tank bioreactor}

All cultivation experiments were conducted in a 5-L stirred tank bioreactor (BIOSTAT B-DCU, Sartorius Stedim, Germany). The bioreactor was equipped with dissolved oxygen, $\mathrm{pH}$, temperature, and foam control systems. The standard six-bladed Rushton turbine impeller (diameter $=0.05 \mathrm{~m}$ ) was used for bubble dispersion and mixing while the ring sparger was used for air sparging. The medium $(3.6 \mathrm{~L})$ in the bioreactor was heat sterilized at $121^{\circ} \mathrm{C}$ for $20 \mathrm{~min}$. The sterilized bioreactor was inoculated with $400 \mathrm{~mL}$ of inoculum $(11 \% \mathrm{v} / \mathrm{v})$ to start the cultivation. The temperature within the bioreactor vessel was controlled at $30^{\circ} \mathrm{C}$ throughout the cultivation. The culture $\mathrm{pH}$ was not controlled but monitored throughout the cultivation. Silicone KM72FS (Shin-Etsu, Japan) at a concentration of $10 \%(\mathrm{v} / \mathrm{v})$ was used as an antifoam agent to control foaming.

Different dissolved oxygen tension (DOT) control strategies were applied to the cultivation of B. thuringiensis MPK13 in the 5-L stirred tank bioreactor, as stated below:

Single-phase DOT control:

1) DOT was set at $80 \%$ throughout the cultivation

2) DOT was set at $60 \%$ throughout the cultivation

3) DOT was set at $40 \%$ throughout the cultivation

Two-phase DOT control:

4) DOT was initially set at $80 \%$ and subsequently set to $60 \%$ at $6 \mathrm{hr}$ of cultivation

5) DOT was initially set at $80 \%$ and subsequently set to $40 \%$ at $6 \mathrm{hr}$ of cultivation

6) DOT was initially set at $60 \%$ and subsequently set to $80 \%$ at $6 \mathrm{hr}$ of cultivation

7) DOT was initially set at $40 \%$ and subsequently set to $80 \%$ at $6 \mathrm{hr}$ of cultivation 
The DOT profiles were decided upon the previous finding by Ghribi et al. (2007) and Kheder et al. (2014). Based on their findings, the level of dissolved oxygen in the culture medium plays a crucial role in the metabolism involved in biopesticide production. The DOT in the culture was measured using a polarographic dissolved oxygen electrode (Hamilton, Germany). In all cultivations, the airflow rate was fixed at $4 \mathrm{~L} / \mathrm{min}(1 \mathrm{vvm})$. The DOT level was controlled at the required value by varying the agitation speed ranging from 50 to $500 \mathrm{rpm}$ using a cascade model of the DOT control module.

\section{Analysis of gaseous exchange during cultivation}

The gaseous exchange during the cultivation was analyzed using the Exhaust Gas Analyser System (EGAS) (Sartorius Stedim, Germany). A gas analyzer type "EL3020", was included in the EGAS-L system to continuously analyze the composition of exhaust gas from the bioreactor. The gas sample was removed from the bioreactor exhaust gas line and fed through the multiplexer controller, which was then forwarded into the EGAS-L for the evaluation of the composition in a pressure-free condition.

The carbon dioxide evolution rate (CER) was calculated by analyzing the difference between the rate of carbon dioxide at the outlet and the inlet divided by the volume of the culture. Several assumptions made in $\mathrm{O}_{2}, \mathrm{CO}_{2}, \mathrm{OUR}, \mathrm{CER}$, and RQ analyses were as follows:

1) The ambient concentrations of $\mathrm{O}_{2}$ and $\mathrm{CO}_{2}$ were $20.9 \%$ and $0.03 \%$, respectively.

2) The gases consumed and evolved during the cultivation were only $\mathrm{O}_{2}$ and $\mathrm{CO}_{2}$, respectively. Other gasses were considered inert.

3) Density and molecular weight of oxygen were $1.41 \mathrm{~g} / \mathrm{L}$ and $32 \mathrm{~g} / \mathrm{mol}$, respectively

4) The density and molecular weight of carbon dioxide were $1.95 \mathrm{~g} / \mathrm{L}$ and $44 \mathrm{~g} / \mathrm{mol}$, respectively.

\section{Total Viable Cell Count}

During the cultivation, culture samples were collected at different time intervals for analysis. The culture samples were serially diluted using $0.85 \%$ $(\mathrm{v} / \mathrm{v})$ saline buffer and plated on nutrient agar (NA) plates via the pour plate method. The plates were incubated at $30^{\circ} \mathrm{C}$ for $48 \mathrm{hr}$ and the number of the single colonies formed was counted and expressed in $\mathrm{cfu} / \mathrm{mL}$. The plates were prepared in triplicates.

\section{Spore Count}

Culture samples were heated to $80^{\circ} \mathrm{C}$ for $15 \mathrm{~min}$ to eliminate vegetative cells before being serially diluted and plated on NA plates. The plates were incubated at $30^{\circ} \mathrm{C}$ for $48 \mathrm{hr}$ and the number of the single colonies formed was counted and expressed as spore $/ \mathrm{mL}$. Spores were counted by the pour-plate counting technique after heat shock (Thompson and Stevenson, 1984) and expressed as spore $/ \mathrm{mL}$. The plates were prepared in triplicates.

The percentage of sporulation was expressed using the following formula:

$$
[(\text { Spore count } \mid \text { cell number })] \times 100
$$

\section{Kinetic data analysis}

The following simplified batch culture kinetic models for cell growth based on the logistic equation, which has been described elsewhere (Ariff et al., 1997), was used to evaluate the growth kinetics of B. thuringiensis MPK13,

Cell growth:

$$
\frac{d X}{d t}=\left[\mu^{\max }\left(1-X / X^{\max }\right)\right]
$$

where $\mathrm{X}$ is the cell concentration $(\mathrm{g} / \mathrm{L}), \mathrm{X}_{\max }$ is the maximum cell concentration $(\mathrm{g} / \mathrm{L}), \mu_{\max }$ is maximum specific growth rate $(1 / \mathrm{h})$ and $t$ is the cultivation time (hr).

The growth kinetic model (Equation 1) was fitted to the experimental data by non-linear regression with a Marquardt algorithm using SIGMA PLOT 10 computer software. The model parameter values were first evaluated by solving equation 1 and then the computer program was used to minimize the sum of squares of the differences between the predicted and measured values (Weiss \& Ollis, 1980; Mohamed et $a l ., 2012)$. The predicted values were then used to simulate the profiles of the cell during the cultivation.

\section{Detection of $\delta$-endotoxin}

SDS-PAGE analysis was used for the detection of $130 \mathrm{kD} \delta$-endotoxin during sporulation (Masri et al., 2020; 2013). The system used in this study is a discontinuous SDS system that is the most widely used electrophoretic system (Lemmli, 1970). The resolution in a Lemmli gel is excellent because the treated peptides are concentrates in a stacking gel before entering the separating gel. To set up two sets of gels for the Hoefer unit, running gel consisting of $5 \mathrm{~mL}$ monomer solution (A: B), $15 \mathrm{~mL} 4 \times$ running buffer $600 \mu \mathrm{L}, 10 \%$ of SDS, and $29.1 \mathrm{~mL}$ of distilled water. The gel solution was vacuumed for $15 \mathrm{~min}$ and after that $300 \mu \mathrm{L}$ of $10 \%$ ammonium persulphate and $20 \mu \mathrm{L}$ of Temed were added. The ammonium persulphate must be prepared fresh. The running gel solution was poured into the Hoefer unit. Stacking gel contains $2.6 \mathrm{~mL}$ monomer (A: B), an aliquot of $5 \mathrm{~mL}$ stacking gel buffer, and $200 \mu \mathrm{L} \mathrm{10 \%} \mathrm{SDS.} \mathrm{Before}$ the samples were loaded into the gel, an aliquot of $2 \times$ treatment buffer was added and incubated in a 
water bath at $100^{\circ} \mathrm{C}$ for $90 \mathrm{~s}$. An aliquot of $80 \mu \mathrm{L}$ of each sample was loaded into each well of the gel. Aliquot of $10 \mu \mathrm{L}$ of $10 \mathrm{kD}$ marker was also loaded into the gel. After the samples were loaded into the wells, the electric current was set up at $15 \mathrm{amps}$ and left overnight.

\section{RESULTS AND DISCUSSION}

\section{B. thuringiensis cultivation without DOT control}

The profile of cell growth and sporulation without DOT control throughout the cultivation is shown in Figure 1 . The highest cell count $\left(1.1 \times 10^{12}\right.$ $\mathrm{cfu} / \mathrm{mL})$, spore count $\left(3.8 \times 10^{11}\right.$ spore $\left./ \mathrm{mL}\right)$ and percentage of sporulation (35\%) were recorded at 48 hr of cultivation (Table 1). Although substantially high cell count $\left(\geq 1.0 \times 10^{12} \mathrm{cfu} / \mathrm{mL}\right)$ was obtained in the cultivation without DOT control, the sporulation was low. The final spore count obtained in this cultivation was only $4.0 \times 10^{11}$ spore $/ \mathrm{mL}$. A reduced maximum specific growth rate $\left(0.05 \mathrm{~h}^{-1}\right)$ was also recorded during the exponential growth phase of the culture without DOT control. Low $\mathrm{CO}_{2}$ value $(0.08 \%)$, OUR $(30 \mathrm{mM} / \mathrm{L} / \mathrm{h})$ and CER $(1 \mathrm{mM} / \mathrm{L} / \mathrm{h})$ were also recorded at $6 \mathrm{hr}$ of cultivation. Nonetheless, the RQ value was above 0.05 (Table 1 ). It is interesting to note that $\delta$-endotoxin was not detected in the cultivation where DOT was left uncontrolled throughout the process.

Effect of single-phase DOT control on growth, sporulation, and d-endotoxin synthesis

The maximum viable cell count (ranging from $1.1 \times 10^{12} \mathrm{cfu} / \mathrm{mL}$ and $1.4 \times 10^{12} \mathrm{cfu} / \mathrm{mL}$ ) was recorded at different DOT control strategies applied in this study (Figure 1A). However, a high maximum specific growth rate $\left(\mu_{\max }\right)$ (above $0.1 \mathrm{~h}^{-1}$ ) was observed in the cultivation where the DOT was controlled at a high level ( $80 \%$ saturation) during the active growth phase as compared to that in the cultivation where the DOT was controlled at lower levels $(40 \%$ or $60 \%$ saturation).

Cultivation with the single-phase DOT control also recorded a low spore count $\left(<5.0 \times 10^{11}\right.$ spore/ $\mathrm{mL})$ and a low percentage of sporulation $(<45 \%)$. The degree of sporulation was greatly reduced when the DOT was controlled at $80 \%$ throughout the cultivation, which gave a final spore count of only $4.2 \times 10^{11}$ spore/mL (Figure 1B). A higher sporulation rate $(>35 \%)$ was obtained in the cultivation where the DOT was controlled at lower levels $(60 \%$ or $40 \%$ saturation) throughout the process as compared to $80 \%$ saturation (Figure 1C). It is important to note that $\delta$-endotoxin was only detected in the cultivation of B. thuringiensis MPK13 where the DOT was controlled at $80 \%$ saturation (Figure $2 \mathrm{~A}$ ), indicating that a high DOT was a crucial factor for $\delta$-endotoxin synthesis.

We found that during the initial growth phase of $B$. thuringiensis MPK13, DOT of $80 \%$ saturation was required to enhance cell growth with a higher maximum specific growth rate exceeded $0.1 \mathrm{~h}^{-1}$ compared to lower aeration (DOT of $60 \%$ or $40 \%$ oxygen saturation) throughout the fermentation. In this study, lower aeration of $60 \%$ or $40 \%$ DOT did not record any production of $\delta$-endotoxin throughout the cultivation. Production of $\delta$-endotoxin was recorded only in cultivation where the initial DOT was set at $80 \%$. This may be due to sufficient aeration during $B$. thuringiensis cultivation since the bacterium is a facultative microorganism and grows well in an aerobic environment. A similar observation was also reported by Khedher et al. (2014) where lower aeration (40\% saturation) throughout the fermentation, significantly reduced the toxin synthesis.

A high dissolved oxygen concentration increased the cell's capacity to metabolize glucose and to produce delta-endotoxins. An adequate quantity of glucose supplied in the culture medium is required to promote high cell growth, sporulation, and formation of $\delta$-endotoxin. Glucose also contributes to better cell morphology and crystalline protein production. The existence of $\delta$-endotoxin was also observed in cultivation using a mixture of various sugars (fructose, sucrose, maltose, and lactose) with $8 \mathrm{~g} / \mathrm{L}$ glucose, indicating that high glucose $(>8 \mathrm{~g} / \mathrm{L})$ must be present in the culture to trigger $\delta$-endotoxin formation in the spores of $B$. thuringiensis MPK13 (Mazmira et al., 2013). Besides glucose, the importance of optimizing the adequate concentration of dissolved oxygen has been reported as one of the crucial factors in the success of $B$. thuringiensis cultivation (Foda et al., 1985; Rossa \& Mignone 1995; Morris et al., 1996). The level of DOT during $B$. thuringiensis cultivation significantly not only affects the cell density but also $\delta$-endotoxin synthesis (Ghribi et al., 2007; Berbert-Molina et al., 2008). In this study, we found that the DOT of $80 \%$ saturation throughout the cultivation was required for optimized $B$. thuringiensis growth rate, however, the production of $\delta$-endotoxin was slow and was recorded only at $48 \mathrm{hr}$ of fermentation. A new cultivation strategy via aeration profiles must be exploited for faster production of $\delta$-endotoxin during the cultivation.

\section{Effect of two-phase DOT control strategy on growth, sporulation and $\boldsymbol{\delta}$-endotoxin synthesis}

The two-phase DOT control strategy provides a substantial improvement in the percentage of sporulation (57-61\%) with a final spore count of $7.9-8.5 \times 10^{11}$ spore $/ \mathrm{mL}$ was obtained in cultivation 
(A)

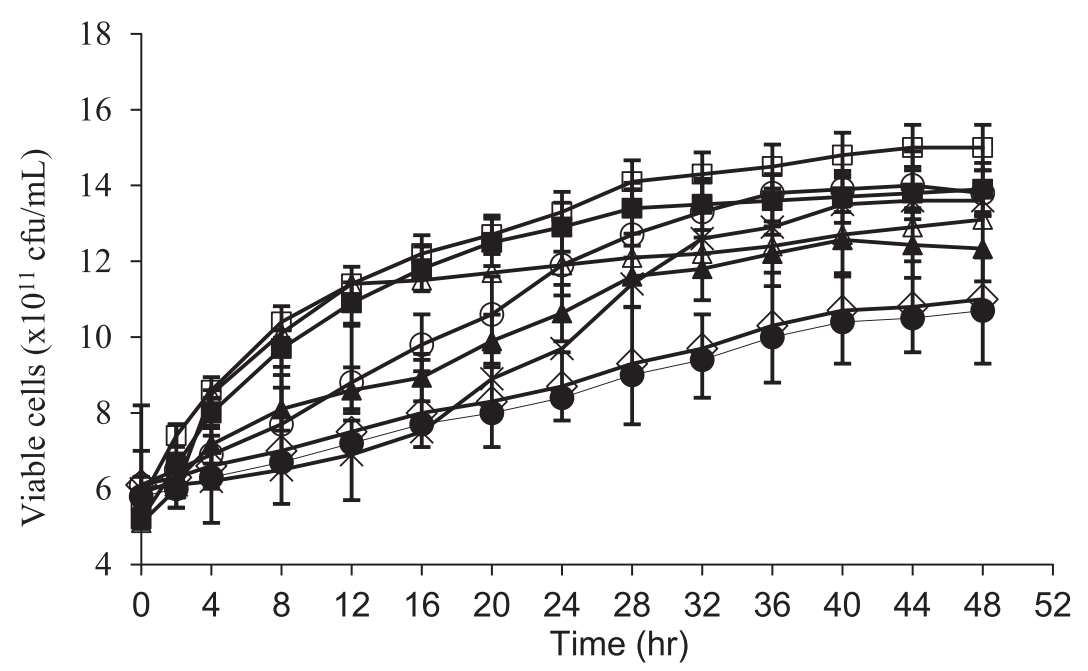

(B)

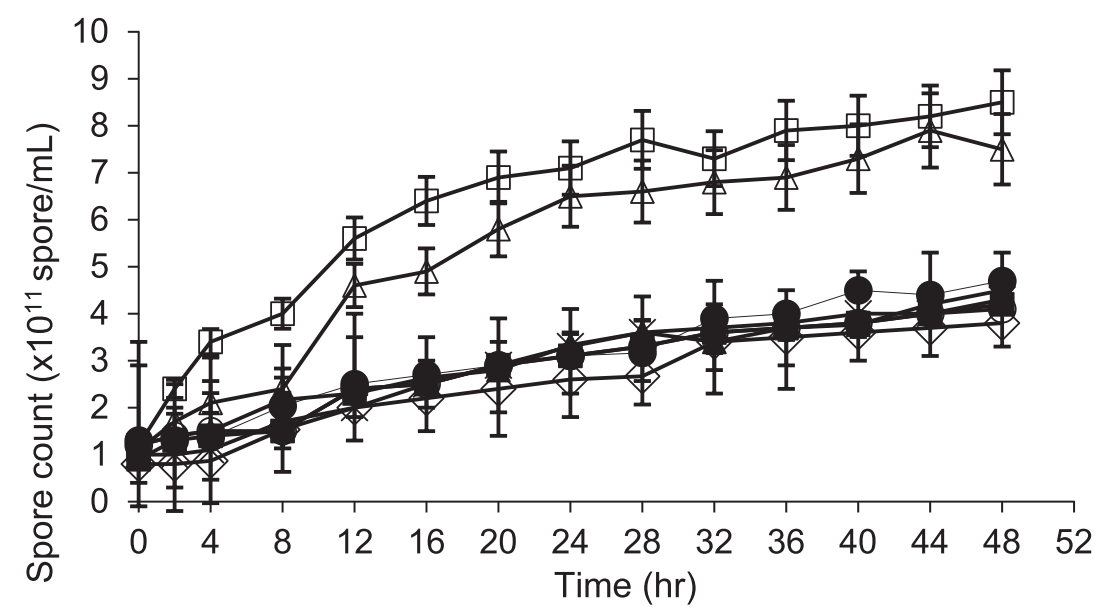

(C)

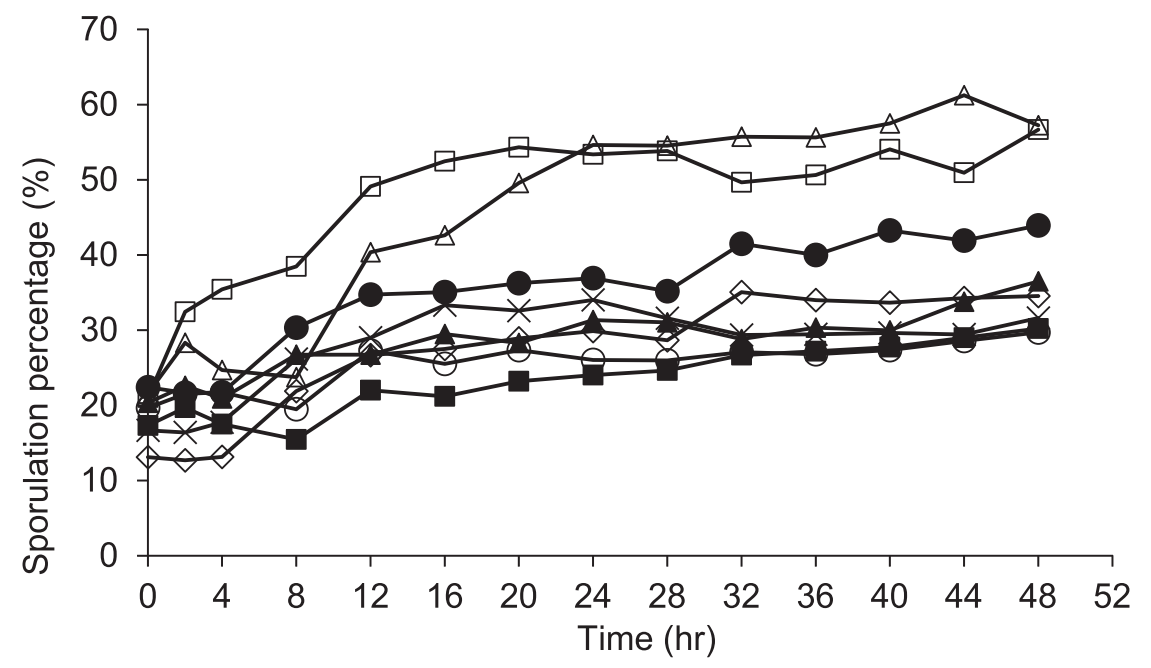

Fig. 1. Growth (A), sporulation (B) and sporulation percentage (C) profiles of Bt MPK13 cultivated in $5 \mathrm{~L}$ stirred tank bioreactor at different DOT control strategies. Controlled DOT (80\%); $\square$ DOT was controlled at $80 \%$ and switch to $60 \%$ at $6 \mathrm{hr}$ of cultivation; $\boldsymbol{\Delta}$ Controlled DOT $(60 \%), \triangle \mathrm{DOT}$ was controlled at $80 \%$ and switch to $40 \%$ at $6 \mathrm{hr}$ of cultivation, Controlled DOT $(40 \%)$, O DOT was controlled at $60 \%$ and switch to $80 \%$ at $6 \mathrm{hr}$ of cultivation, $\times$ DOT was controlled at $40 \%$ and switch to $80 \%$ at $6 \mathrm{hr}$ of cultivation, $\diamond$ Without DOT control (aeration rate $1 \mathrm{vvm}$, agitation speed fixed at $200 \mathrm{rpm}$. 


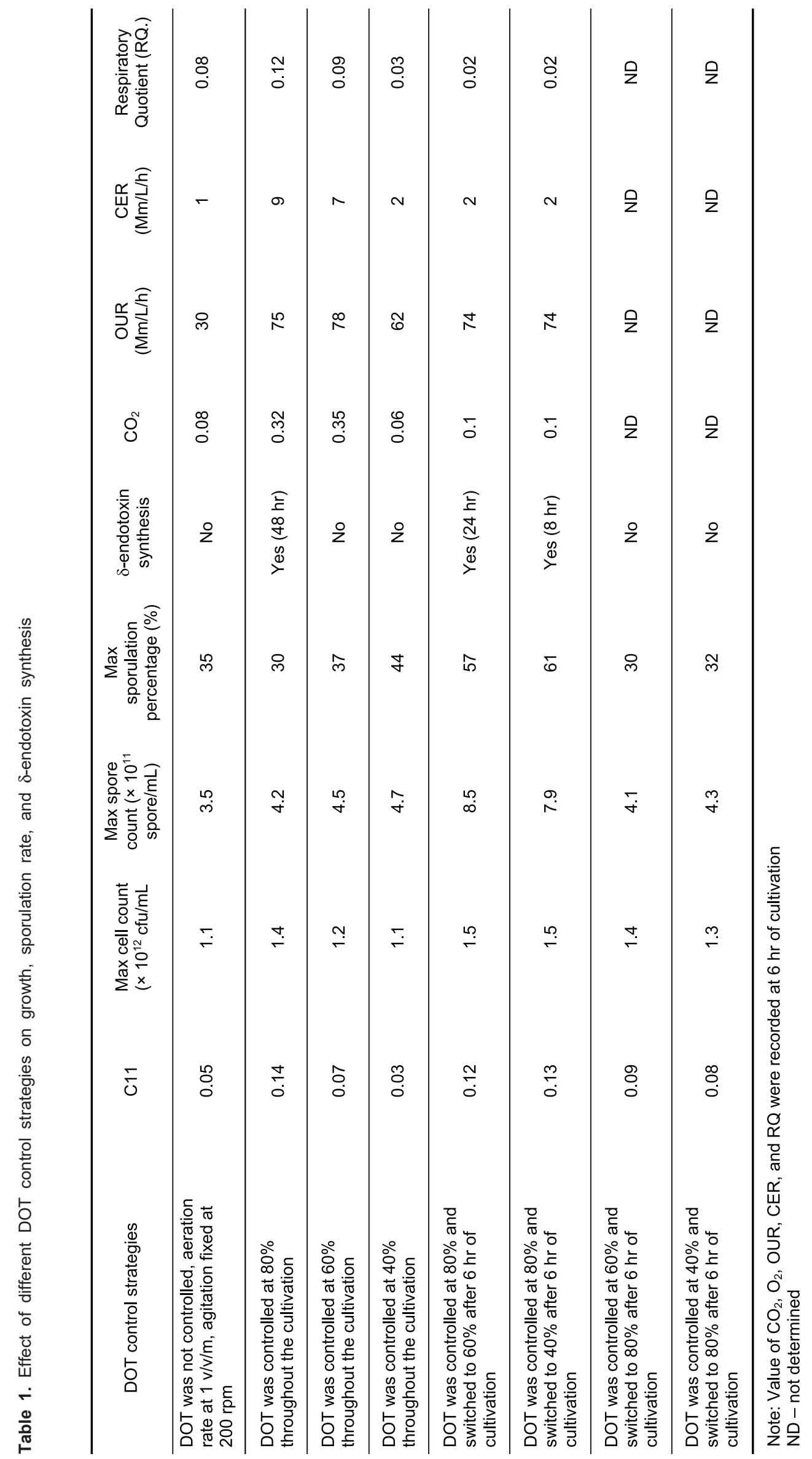


(A)

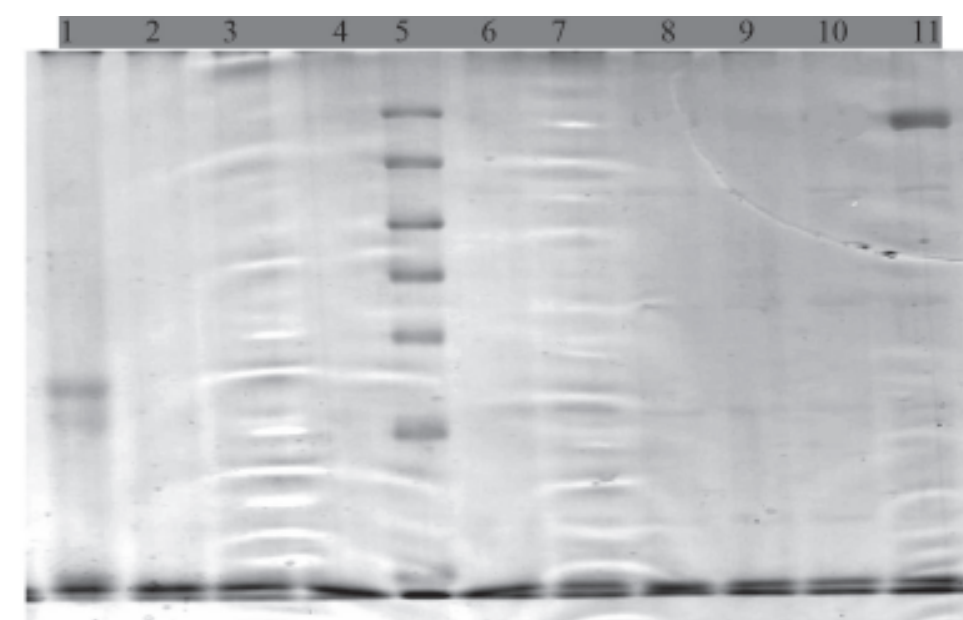

$170 \mathrm{kD}$

$130 \mathrm{kD}$ ( $\delta$-endotoxin)

$110 \mathrm{kD}$

$95 \mathrm{kD}$

$72 \mathrm{kD}$

$55 \mathrm{kD}$

$43 \mathrm{kD}$

$26 \mathrm{kD}$

$17 \mathrm{kD}$

(B)
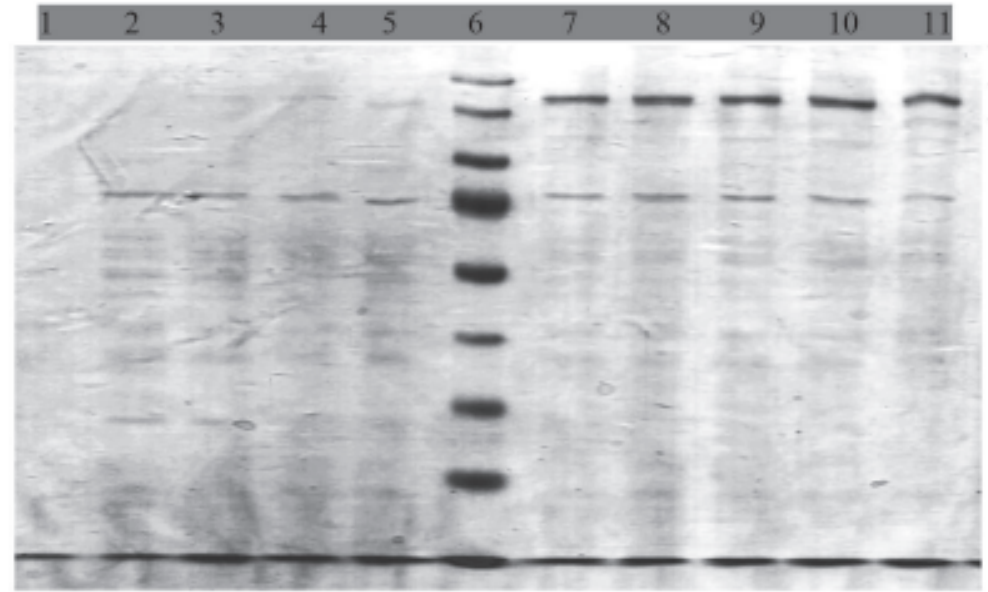

$170 \mathrm{kD}$

$130 \mathrm{kD}$ (8-endotoxin)

$110 \mathrm{kD}$

$95 \mathrm{kD}$

$72 \mathrm{Kd}$

$55 \mathrm{kD}$

$43 \mathrm{kD}$

$26 \mathrm{kD}$

$17 \mathrm{kD}$

(C)

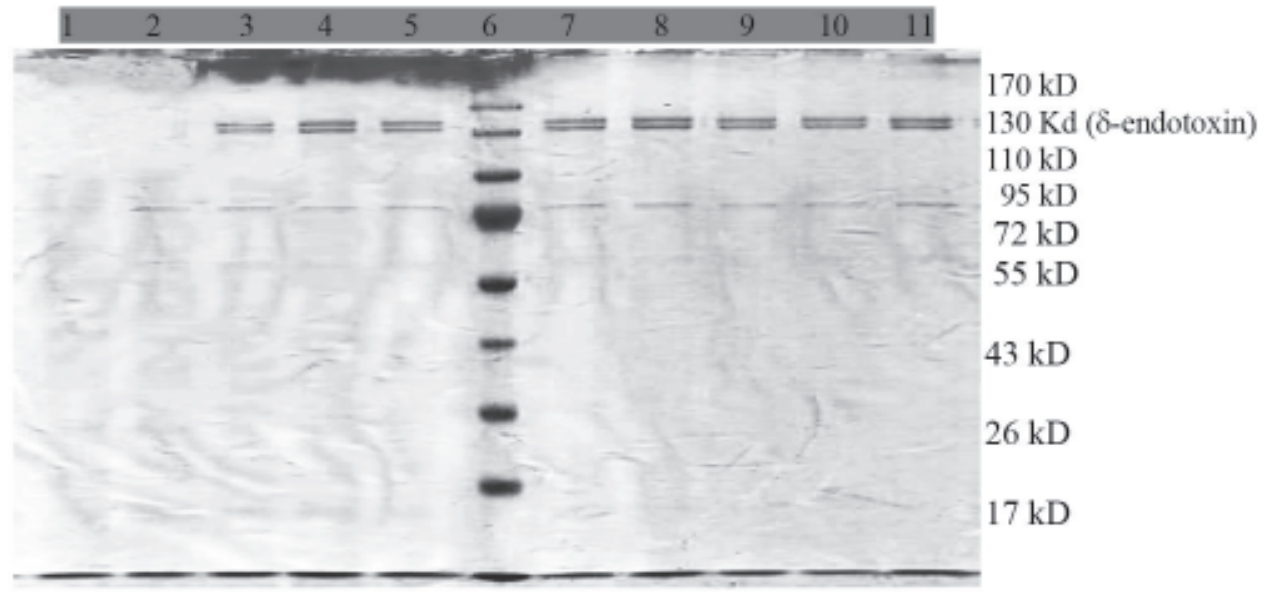

Fig. 2. SDS-PAGE analysis of Bt MPK13 samples from culture with (A) Controlled DOT of 80\% saturation throughout the cultivation (Lane 1: $0 \mathrm{hr}$; Lane 2: $4 \mathrm{hr}$; Lane 3: $8 \mathrm{hr}$; Lane 4: $12 \mathrm{hr}$; Lane 5: broad range protein marker, MBiotech, Korea; Lane 6: $16 \mathrm{hr}$; Lane 7: $24 \mathrm{hr}$; Lane 8: $28 \mathrm{hr}$; Lane 9: $36 \mathrm{hr}$; Lane 10: $40 \mathrm{hr}$; Lane 11: $48 \mathrm{hr}$ ); (B) DOT was controlled at $80 \%$ and switch to $60 \%$ at $6 \mathrm{hr}$ of cultivation (Lane 1: $0 \mathrm{hr}$; Lane 2: $4 \mathrm{hr}$; Lane 3: $8 \mathrm{hr}$; Lane 4: $12 \mathrm{hr}$; Lane 5: $16 \mathrm{hr}$; Lane 6: broad range protein marker, MBiotech, Korea; Lane 7: $24 \mathrm{hr}$; Lane 8: $28 \mathrm{hr}$; Lane 9: $36 \mathrm{hr}$; Lane 10: $40 \mathrm{hr}$; Lane 11: $48 \mathrm{hr}$ ); (C) DOT was controlled at 80\% and switch to 40\% at $6 \mathrm{hr}$ of cultivation (Lane 1: $0 \mathrm{hr}$; Lane 2: $4 \mathrm{hr}$; Lane 3: $8 \mathrm{hr}$; Lane 4: $12 \mathrm{hr}$ : Lane 5: $16 \mathrm{hr}$; Lane 6: broad range protein marker, MBiotech, Korea; Lane 7: $24 \mathrm{hr}$; Lane 8: $28 \mathrm{hr}$; Lane 9: $36 \mathrm{hr}$; Lane 10: $40 \mathrm{hr}$; Lane 11: 48 hr). Note: $\mathrm{kD}=$ kilodalton. 
where the DOT was controlled at $80 \%$ saturation during active growth and then switched to either $60 \%$ or $40 \%$ saturation after $6 \mathrm{hr}$ (Figure 1B). A higher maximum specific growth rate, ranging from 0.12 to $0.13 \mathrm{~h}^{-1}$, was also recorded in cultivation using the two-phase DOT control (Table 1). Faster production of $\delta$-endotoxin was also detected in these cultivations.

In cultivation where the DOT profile was switched from lower to higher saturation after $6 \mathrm{hr}$ of fermentation, a reduced sporulation percentage from $30-32 \%$ was recorded. A reduced maximum specific growth rate $\left(<0.1 \mathrm{~h}^{-1}\right)$ was also observed in these cultivations. It was observed that $\delta$-endotoxin synthesis was not detected in cultivations where the DOT was controlled at a value lower than $80 \%$ saturation during the initial stages of the cultivation (Table 1).

During the two-phase DOT control strategy, where DOT was initially controlled at a high level ( $80 \%$ saturation) and then switched to a lower level ( $40 \%$ or $60 \%$ saturation) after $6 \mathrm{hr}$, thick bands of $\delta$-endotoxin at the molecular weight of $130 \mathrm{kD}$ was detected at 24 to $48 \mathrm{hr}$ of cultivation (Figure 2B). Synthesis of $\delta$-endotoxin was obtained at $8 \mathrm{hr}$ of cultivation where the DOT was controlled at $80 \%$ and switched to $40 \%$ saturation. The intensity of the bands remained constant until $48 \mathrm{hr}$ of cultivation (Figure 2C). The synthesis of $\delta$-endotoxin at $8 \mathrm{hr}$ of cultivation was a response to drastic changes in DOT changes at $6 \mathrm{~h}$ of cultivation. Results from this study indicated that high DOT level during active growth was required not only to support high cell growth but also to enhance sporulation and $\delta$-endotoxin. The interruption of DOT level in the culture with actively growing cells may change the cell metabolism, which in turn, sporulation and $\delta$-endotoxin synthesis were further enhanced.

An aeration strategy that supports both high cell count and spore count in the culture is vital to trigger the $\delta$-endotoxin production. Taking into consideration all effects of aeration, it can be concluded that carrying out high aeration level during the first $6 \mathrm{hr}$ of culture followed by a moderate oxygenation rate up to the end of fermentation could induce an increase in deltaendotoxin production and an improvement in $B$. thuringiensis toxicity (Khedher et al., 2014). High cell count and also high spore count are crucial for $B$. thuringiensis cultivation as it is coupled with the production of $\delta$-endotoxin ( $\mathrm{Vu}$ et al., 2012). High dissolved oxygen during the exponential growth phase is important for the production of $B$. thuringiensis spores (Silveira \& Molina et al., 2005). However, a very high DOT level (100\% saturation) was not preferred for $B$. thuringiensis cultivation (Sarrafzadeh et al., 2006), in which, saturated rich oxygen condition would affect cell growth and cease the onset of sporulation. A rich oxygen environment in the culture is not suitable for sporulation since it can stunt the process (Saraffzadeh et al., 2007). Changes in DOT level during the cultivation have been proven to manipulate the spore production (Ghribi et al., 2007; Berbert-Molina et al., 2008). The toxicity of Bacillus spp. was also affected by the DOT level, where a high DOT level (100\%) causes a reduction in toxicity (Ismail et al., 1996). Low metabolism is one of the criteria required for the cells to sporulate and produce $\delta$-endotoxin. In this study, we found that the presence of high viable cells in the culture is needed for high spore count and the right aeration profiles from high to lower DOT must be applied at $6 \mathrm{hr}$ of fermentation for faster production of $\delta$-endotoxin.

The two-phase DOT control strategy $(80 \%$ saturation during the initial active growth phase and then switched to $40-60 \%$ saturation after $6 \mathrm{hr}$ ) as proposed in this study may be applied in the industrial process for enhancement of sporulation rate of $B$. thuringiensis and $\delta$-endotoxin.

\section{Relationship between exhaust gas analysis and B. thuringiensis cultivation performance}

The profile of OUR, CER, and RQ during the cultivation of $B$. thuringiensis MPK13 at different DOT control strategies are shown in Figures 3, 4, and 5 , respectively. The highest OUR $(78 \mathrm{mM} / \mathrm{L} / \mathrm{h})$ was observed in cultivations with a single-phase DOT control strategy ( $80 \%$ and $60 \%$ saturation) (Table 1). Reduced OUR ( $65 \mathrm{mM} / \mathrm{L} / \mathrm{h})$ was observed in cultivation where the DOT was controlled in a single-phase at $40 \%$ saturation.

In cultivation with a two-phase DOT control strategy, higher OUR ranging from $71 \mathrm{mM} / \mathrm{Lh}$ and 78 $\mathrm{mM} / \mathrm{Lh}$, were observed when the DOT was controlled at a high level ( $80 \%$ saturation) during the initial active growth phase (Figure 3). Reduced OUR value was also observed in the two-phase control strategy with DOT lower than $80 \%$ during the initial growth phase. In all cultivations, the OUR value became level off when growth reached a stationary growth phase. It was evident that the high initial DOT level ( $80 \%$ saturation) during initial active growth contributed to high OUR.

The highest CER values for all cultivations were recorded during the initial stage of the exponential growth phase ( $4 \mathrm{hr}$ ). Cultivation with a single-phase DOT control strategy ( $80 \%$ and $60 \%$ saturation) recorded the highest CER $(11 \mathrm{mM} / \mathrm{L} / \mathrm{h})$. In comparison, the cultivation with a two-phase DOT control strategy $(80 \%$ to $40-60 \%)$ recorded the highest CER value $(10 \mathrm{mM} / \mathrm{L} / \mathrm{h})$ during the exponential growth phase (Figure 4). Cultivation with a single-phase DOT control strategy at $40 \%$ 


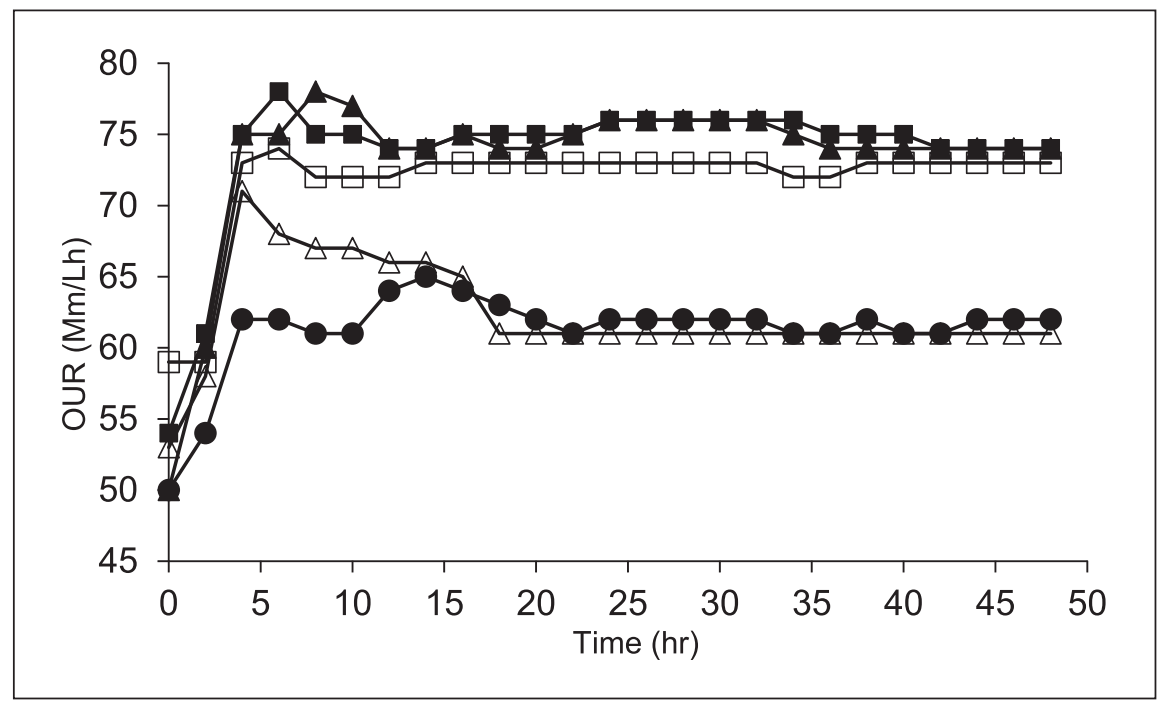

Fig. 3. Oxygen uptake rate (OUR) profile of Bt MPK13 cultivated in $5 \mathrm{~L}$ stirred tank bioreactor at different DOT control strategies. Controlled DOT (80\%); $\square$ DOT was controlled at $80 \%$ and switch to $60 \%$ at $6 \mathrm{hr}$ of cultivation; $\boldsymbol{\Delta}$ Controlled DOT $(60 \%)$, $\triangle$ DOT was controlled at $80 \%$ and switch to $40 \%$ at $6 \mathrm{hr}$ of cultivation, Controlled DOT $(40 \%)$.

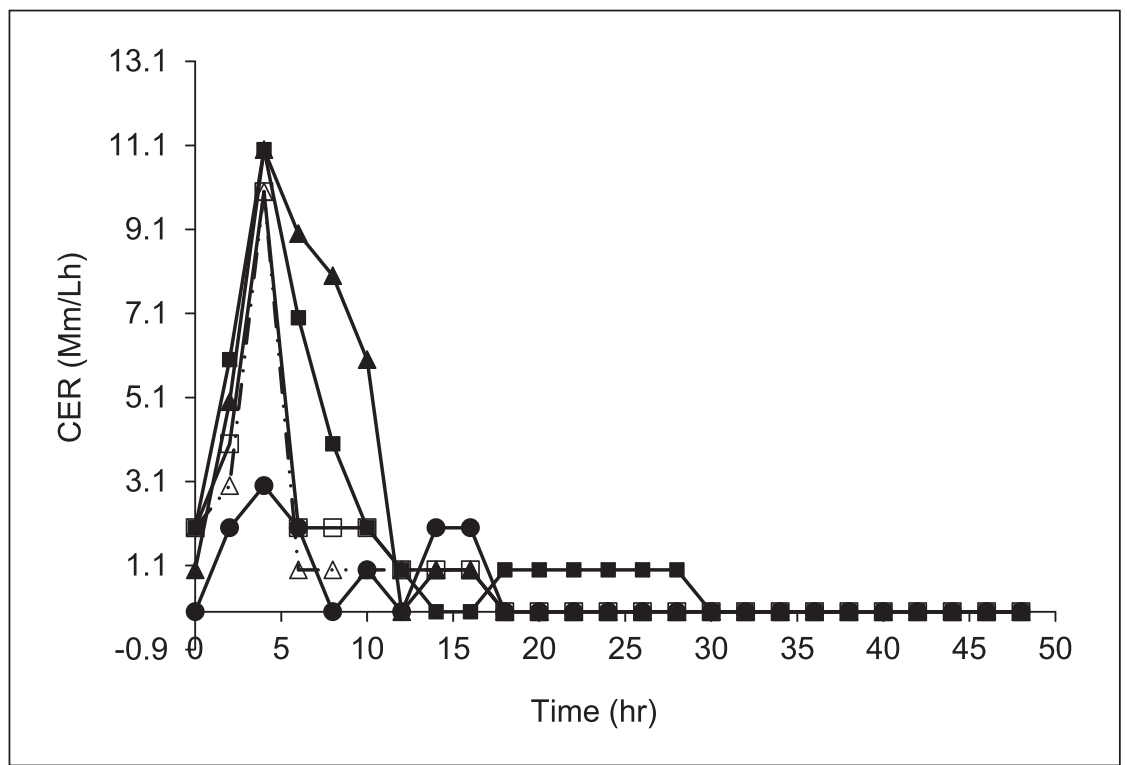

Fig. 4. Carbon dioxide extraction rate (CER) profile of Bt MPK13 cultivated in $5 \mathrm{~L}$ stirred tank bioreactor at different DOT control strategies. Controlled DOT (80\%); $\square$ DOT was controlled at $80 \%$ and switch to $60 \%$ at $6 \mathrm{hr}$ of cultivation; $\boldsymbol{\Delta}$ Controlled DOT $(60 \%), \triangle$ DOT was controlled at $80 \%$ and switch to $40 \%$ at $6 \mathrm{hr}$ of cultivation, - Controlled DOT (40\%).

saturation recorded low CER (ranging from $3 \mathrm{mM} / \mathrm{L} /$ $\mathrm{h}$ to $10 \mathrm{mM} / \mathrm{L} / \mathrm{h}$ ). In all cultivations, CER values were decreased to $0 \mathrm{mM} / \mathrm{Lh}$ after $30 \mathrm{hr}$ of cultivation.

The highest value of respiratory quotient (RQ) in all cultivations was recorded during the initial stage of the exponential growth phase (Figure 5). The profile of RQ was quite similar to the CER profile where all the highest values were recorded at $4 \mathrm{hr}$ of cultivation. The microbial respiratory quotient (RQ), defined as the ratio of $\mathrm{mol} \mathrm{CO}_{2}$ evolution per $\mathrm{mol} \mathrm{O}$ uptake. In this study, the highest value of CER and RQ recorded at $4 \mathrm{hr}$ of cultivation refers to the active growth phase of the cell where the respiration and amount of $\mathrm{CO}_{2}$ emitted by the microbes was higher than the available $\mathrm{O}_{2}$ in the vessel. All cultivations where the DOT was controlled at a high level $(80 \%$ saturation) during the initial active growth phase recorded the highest value of $\mathrm{RQ}$, ranging from 0.14 


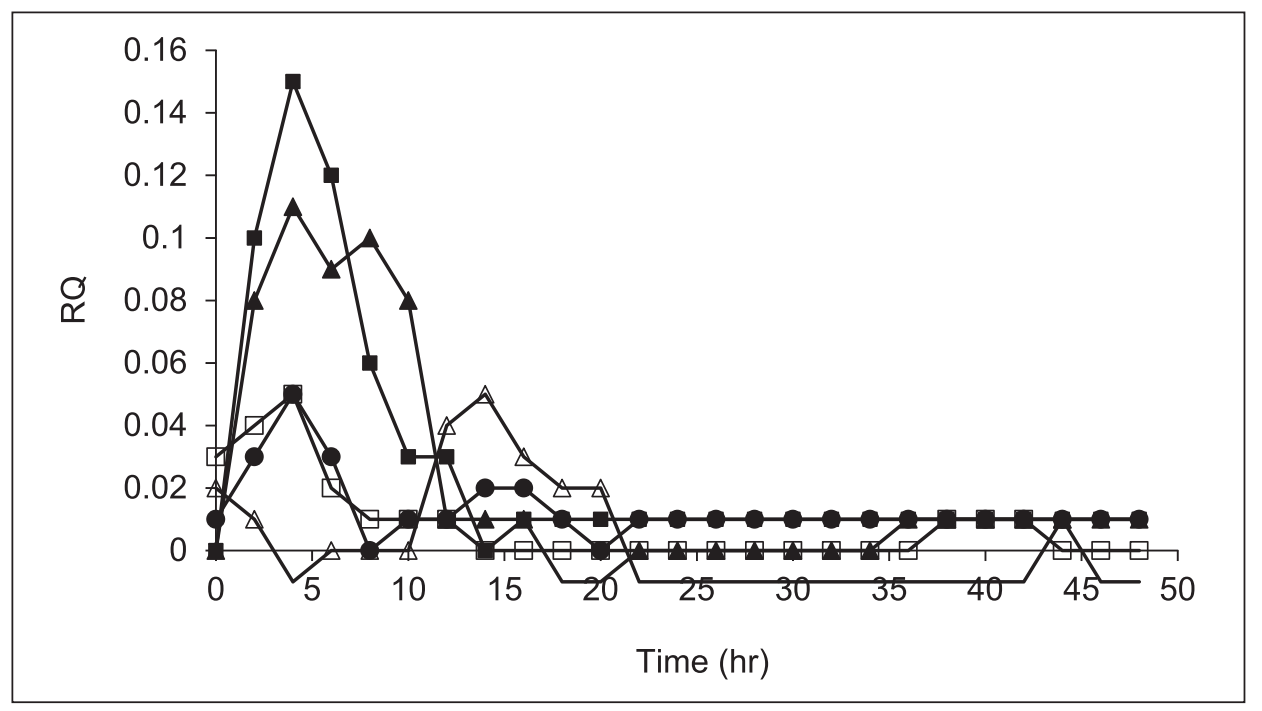

Fig. 5. Respiration quotient (RQ) profile of Bt MPK13 cultivated in 5 L stirred tank bioreactor at different DOT control strategies. Controlled DOT (80\%); $\square$ DOT was controlled at $80 \%$ and switch to $60 \%$ at $6 \mathrm{hr}$ of cultivation; $\Delta$ Controlled DOT $(60 \%), \triangle$ DOT was controlled at $80 \%$ and switch to $40 \%$ at $6 \mathrm{hr}$ of cultivation, Controlled DOT (40\%).

to 0.15 . The highest RQ value for cultivation with a single-phase DOT control strategy at $60 \%$ saturation and $40 \%$ saturation was 0.12 and 0.05 , respectively (Figure 5). In all cultivations, the reduced value of RQ (0.01) was observed after $20 \mathrm{hr}$. It is interesting to note that the CER and RQ values for cultivation with a two-phase DOT control strategy decreased drastically after $6 \mathrm{hr}$, as compared to those recorded in cultivations with a single-phase DOT control strategy. These results showed that in a stirred tank bioreactor, the requirement of dissolved oxygen during each growth phase played a crucial role in producing $\delta$-endotoxin. It was found that the dissolved oxygen was required during the first $6 \mathrm{hr}$ of vegetative growth for regulating the carbon source assimilation rate. The requirement to decrease oxygen saturation after $6 \mathrm{hr}$ of vegetative growth could be explained by additional time for cry gene expression and crystal formation (Zouari \& Jaoua, 1999).

The relationship between OUR and CER in $B$. thuringiensis cultivation and other microbes has not been well documented. The only report available in the literature on the relationship between OUR and CER was on aerobic thermophilic sludge digestion (Kovacs et al., 2007). In this study, the CER and RQ values in cultivation with a two-phase DOT control strategy ( $80 \%$ to $40-60 \%$ saturation) greatly varied as compared to the values recorded in a single-phase DOT control strategy. The OUR value did not significantly vary in all cultivation except for cultivation where the DOT was controlled at a low level (40\% saturation) during the initial active growth phase. High CER indicated that the rate of $\mathrm{CO}_{2}$ exiting the bioreactor was high. As respiration produces $\mathrm{CO}_{2}$, this meant that the cells were actively growing.
High cell count obtained in cultivation with high DOT level ( $80 \%$ saturation) during active growth was concurrent with high cell count, high $\mu_{\max }$, fast generation time, high OUR, high CER value, and high RQ value. High OUR value recorded during the onephase DOT control strategy of $80 \%$ saturation correlates to high cell count during the exponential phase. Rowe et al. (2003) also reported a similar situation with high OUR value that was achieved during inoculation and throughout the exponential growth phase of batch cultivation.

Low respiratory quotient (RQ) values were also reported during the two-phase DOT control strategy. The low RQ values in the cultures contribute to higher sporulation and $\delta$-endotoxin production. RQ value is particularly useful for understanding cell metabolism. It can be defined as the ratio of the number of $\mathrm{CO}_{2}$ molecules produced by an organism to the number of $\mathrm{O}_{2}$ molecules consumed. It means that cell metabolism can be compared at different conditions by referring to the RQ value. Detail study on the relationship of RQ value with the results from this study indicated that the RQ value for the cultivation where the DOT was controlled at $80 \%$ and $60 \%$ was higher than the values recorded in cultivation where the DOT was controlled at a low level (40\% saturation) during the initial active growth phase. The evaluation of exhaust gas during the cultivation enables the calculation of several parameters (OUR, CER, and RQ), which can be used for on-line monitoring of the $B$. thuringiensis cultivation performance. However, for this study, a further study on mechanistic (physiological and metabolic) details should be carried out and analyzed for $\delta$-endotoxin production at lower DOT levels. 


\section{CONCLUSION}

Results from this study demonstrated that cell growth, sporulation rate, and $\delta$-endotoxin synthesis of $B$. thuringiensis were greatly influenced by different DOT control strategies during the cultivation. The optimal DOT control strategy for enhancement of sporulation (up to $61 \%$ ) and $\delta$ endotoxin synthesis recorded as early as $8 \mathrm{hr}$ of cultivation was obtained in the two-phase DOT strategy with $80 \%$ saturation and then switched to $40 \%$ after $6 \mathrm{hr}$. On the contrary, $\delta$-endotoxin in singlephase DOT control at $80 \%$ saturation was recorded only after $48 \mathrm{hr}$ of the cultivation, and disrupt the B. thuringiensis sporulation potential. It is essential to achieve a maximum specific growth rate, $\mu_{\max }$ values exceeded $0.1 \mathrm{~h}^{-1}$ for constant $\delta$-endotoxin production during $B$. thuringiensis MPK13 cultivation. Results from this study also demonstrated the potential of exhaust gas analysis that could be used for quick monitoring of $B$. thuringiensis cultivation performance for the production of spores with high bioinsecticidal activity.

\section{ACKNOWLEDGEMENTS}

The authors would like to thank the Director-General of the Malaysian Palm Oil Board for permission to publish this article. We appreciate all staff from Microbial Technology and Engineering Center (MICROTEC) for the assistance to conduct this study. The study was supported financially by MPOB.

\section{REFERENCES}

Amicarelli, A., di Sciascio, F., Toibero, J.M. \& Alvarez, H. 2010. Including dissolved oxygen dynamics into the $\mathrm{Bt}$ d-endotoxins production process model and its application to process control. Brazilian Journal of Chemical Engineering, 27: 41-62.

Ariff, A.B., Rosfarizan, M., Herng, L.S., Madihah, S. \& Karim, M.I.A. 1997. Kinetics and modelling of kojic acid production by Aspergillus flavus Link in batch fermentation and resuspended mycelial system. World Journal of Microbiology and Biotechnology, 13: 195-201.

Aronson, A. 2002. Sporulation and $\delta$-endotoxin synthesis by Bacillus thuringiensis. Cellular and Molecular Life Sciences, 59: 417-425.

Avignone-Rossa, C., Arcas, J. \& Mignone, C. 1992. Bacillus thuringiensis growth, sporulation and delta-endotoxin production in oxygen limited and non-limited cultures. World Jorunal of Microbiology and Biotechnology, 8: 301-304.
Berbert-Molina, M.A., Prata, A.M.R., Pessanha, L.G. \& Silveira, M.M. 2008. Kinetics of Bacillus thuringiensis var. israelensis growth on high glucose concentrations. Journal of Industrial Microbiology and Biotechnology, 35: $1397-$ 1404.

Bravo, A., Likitvivatanavong, S., Gill, S.S. \& Soberon, M. 2011. Bacillus thuringiensis: A story of a successful bioinsecticide. Insect Biochemistry and Molecular Biology, 2: 423-431.

Boniolo, F.S., Rodrigues, R.C., Prata, A.M, López, M.L., Jacinto, T., da Silveira, M.M. \& BerbertMolina, M.A. 2012. Oxygen supply in Bacillus thuringiensis fermentations: bringing new insights on their impact on sporulation and $\delta$ endotoxin production. Applied Microbiology and Biotechnology, 94: 625-36.

Cheung, W., Xu, Y., Thomas, C.L.P. \& Goodacre, R. 2009. Discrimination of bacteria using pyrolysisgas chromatography-differential mobility spectrometry (Py-GC-DMS) and chemometrics. Analyst, 134: 557-563.

Ghribi, D., Zouari, N., Trabelsi, H. \& Jaoua, S. 2007. Improvement of Bacillus thuringiensis deltaendotoxin production by overcome of carbon catabolite repression through adequate control of aeration. Enzyme and Microbial Technology, 40: 614-622.

Gopinathan, C., Chaudhury, A. \& Vivek, A.T. 2016. Novel techniques for cost-effective production of Bacillus thuringiensis subsp. israelensis. International Journal of Mosquito Research, 3: 17-29.

Ha, S., Kim, H.M., Chun, H.H., Hwang, I.M., Lee, J.H., Kim, J.C., Kim, I.S. \& Park, H.W. 2018. Effect of Oxygen Supply on Surfactin Production and Sporulation in Submerged Culture of Bacillus subtilis Y9. Applied Sciences, 8: 1660.

Hildebrand, F., Meyer, A. \& Walker, A.E. 2010. Evidence of Selection upon Genomic GC-Content in Bacteria. PloS Genetics, 6: 1-9.

Içgen, Y., Içgen, B. \& Ozcengiz, G. 2002. Regulation of crystal protein biosynthesis by Bacillus thuringiensis: II. Effects of carbon and nitrogen sources. Research in Microbiology, 153: 605609.

Ismail, M.A.K. 1996. Effect of dissolved oxygen on the growth, sporulation and larvicidal activity of Bacillus sphaericus 2362. Pertanika Journal of Science \& Technology, 4: 191-196.

Jaquet, F., Hütter, R. \& Lüthy, P. 1987. Specificity of Bacillus thuringiensis delta endotoxin. Applied and Environmental Microbiology, 53: 500-504.

Khedher, S.B., Jaoua, S. \& Zouari, N. 2014. Overcome of carbon catabolite repression of bioinsecticides production by sporeless Bacillus thuringiensis though adequate fermentation technology. 
Biotechnology Research International, 2014: Article ID 698587.

Kim, D.J., Lee, D.I., Chal, G.C. \& Keller, J. 2008. Analysis of Free Ammonia Inhibition of Nitrite Oxidizing Using a Dissolved Oxygen Respirometer Analysis of Free Ammonia Inhibition of Nitrite Oxidizing Using a Dissolved Oxygen Respirometer. Environmental Engineering Research, 13: 125-130.

Kovacs, R., Hazi, F., Csikor, Z. \& Milhatz, P. 2007. Connection between oxygen uptake rate in aerobic thermophilic sludge digestion. Periodica Polytechnica Chemical Engineeering, 51: 17-22.

Kumar, S. \& Singh, A. 2015. Biopesticides: Present status and the future prospects. Journal of Biofertilizer and Biopesticide, 6: e129.

Kuphaldt, T.R. 2008. Lessons in Industrial Instrumentation. San Francisco: Creative Commons. In Physics, 40-42.

Lalke-Porczyk, E. \& Donderski, W. 2001. Metabolic Activity of Epiphytic Bacteria Inhabiting the Common Reed (Phragmites australis (Cav.) Trin. ex Steudel) in Moty Bay of Jeziorak Lake. Polish Journal of Environmental Studies, 10: 443-450.

Maldonado-Blanco, M.G., Solís-Romero, G. \& GalánWong, L.J. 2003. The effect of oxygen tension on the production of Bacillus thuringiensis subsp. israelensis toxin active against Aedes aegypti larvae. World Journal of Microbiology and Biotechnology, 19: 671-674.

Masri, M.M.M., Tan, J.S. \& Ariff, A.B. 2020. Effect of Cry+ Bacillus thuringiensis cells and fermentation condition on consistent production of delta-endotoxin. Asia-Pacific Journal of Science and Technology, 25(02): 1-12.

Masri, M.M.M., Ramlah, S.A.A., Rosfarizan, M., Ling, T.C. \& Ariff, A.B. 2013. Relationship between Total Carbon, Total Nitrogen and Carbon to Nitrogen Ratio on growth, sporulation rate and delta-endotoxin synthesis of Bacillus thuringiensis. Minerva Biotecnologica, 25: 219225.

Mohamed, M.S., Rosfarizan, M., Manan, M.A. \& Ariff, A.B. 2012. Enhancement of red pigment production by Monascus purpureus FTC 5391 through retrofitting of helical Ribbon Impeller in Stirred-Tank Fermenter. Food and Bioprocess Technology, 5: 80-91.

Rowe, G.E., Margaritis, A. \& Wei, N. 2008. Specific Oxygen Uptake Rate Variations during Batch Fermentation of Bacillus thuringiensis subspecies kurstaki HD-1. Biotechnology Progress, 19: 1439-1443.

Sarrafzadeh, M.H., Belloy, L., Esteban, G., Navarro, J.M. \& Ghonmidh, C. 2005. Diaelectric monitoring of growth and sporulation of Bacillus thuringiensis. Biotechnology Letters, 27: 511517.
Sarrafzadeh, M.H., Bigey, F., Capariccio, B., Mehrnia, M.R., Guirau, J.P. \& Navarro, J.M. 2007. Simple indicators of plasmid loss during fermentation of Bacillus thuringiensis. Enzyme and Microbial Technology, 40: 1052-1058.

Sarrafzadeh, M.H. \& Navarro, J.M. 2006. The effect of oxygen on the sporulation, $\delta$-endotoxin of Bacillus thuringiensis H14. World Journal of Microbiology and Biotechnology, 22: 305-310.

Silveira, M.M. \& Molina, M.A.B. 2005. Indirect estimation of Bacillus thuringiensis var. israelensis biomass concentration using oxygen balance data. Brazilian Journal of Chemical Engineering, 22: 495-500.

Stanbury, P.F., Whitaker, A. \& Hall, S.J. 2003. Principles of Fermentation Technology. 2nd Ed. Elsevier, Butterworth-Heinemann. pp.149-151.

Thompson, P.J. \& Stevenson, K.E. 1984. Mesophilic spore forming aerobes. In: Speck, M. (Ed.). In: Compedium of Methods for the Microbiological Examination of Foods. M. Speck (Ed.). American Public Health Association, Washington. pp. 211220.

Vanrolleghem, P.A. 2002. Principles of Respirometry in Activated Sludge Wastewater Treatment. University of Gent Belgium, 1-20.

Vu, K.D., Tyagi, R.D., Surampalli, R.Y. \& Valero, J.R. 2012. Mathematical relationships between spore concentrations, delta-endotoxin levels, and entomotoxicity of Bacillus thuringiensis preparations produced in different fermentation media. Bioresource Technology, 123: 303-311.

Weiss, R.M. \& Ollis, D.F. 1980. Extracellular microbial polysaccharides. I. Substrate, biomass, and product kinetic equations for batch xanthan gum fermentation. Biotechnology and Bioengineering, 22: 859-873.

Zhang, C. \& Hughes, J.B. 2004. Bacterial energetics, stoichiometry, and kinetic modeling of 2,4dinitrotoluene biodegradation in a batch respirometer. Environmental Toxicology Chemistry, 3: 2799-806.

Zouari, N. \& Jaoua, S. 1999. The effect of complex carbon and nitrogen, salt, Tween- 80 and acetate on delta-endotoxin production by a Bacillus thuringiensis subsp kurstaki. Journal of Industrial Microbiology and Biotechnology, 23(6): 497-502.

Zouari, N., Ali, S.B.S. \& Jaoua, S. 2002. Production of delta-endotoxins by Bacillus thuringiensis strains exhibiting various insecticidal activities towards lepidoptera and diptera in gruel and fish meal media. Enzyme and Microbial Technology, 31: 411-418. 